\title{
The Liberty of Limitations: The Paradoxes of Narration in Ben Okri's The Famished Road
}

\section{Kathie Birat}

\section{Q OpenEdition}

1 Journals

Electronic version

URL: https://journals.openedition.org/ces/5372

DOI: $10.4000 /$ ces.5372

ISSN: 2534-6695

Publisher

SEPC (Société d'études des pays du Commonwealth)

\section{Printed version}

Date of publication: 1 April 2013

Number of pages: 101-110

ISSN: 2270-0633

\section{Electronic reference}

Kathie Birat, "The Liberty of Limitations: The Paradoxes of Narration in Ben Okri's The Famished Road", Commonwealth Essays and Studies [Online], 35.2 | 2013, Online since 17 April 2021, connection on 23 July 2021. URL: http://journals.openedition.org/ces/5372 ; DOI: https://doi.org/10.4000/ces.5372

\section{(c) $($ †) $\ominus$}

Commonwealth Essays and Studies is licensed under a Licence Creative Commons Attribution - Pas d'Utilisation Commerciale - Pas de Modification 4.0 International. 


\section{The Liberty of Limitations: The Paradoxes of Narration in Ben Okri's The Famished Road}

This article examines the impact of Azaro's status as narrator and his function within a novel that relies on a number of different literary models, both European and African.

The main focus is on the relationship between the African dimensions of the novel, related to a culture of orality, and those aspects which can be seen as reflecting the narrative conventions of realist fiction. An analysis of Chapter Ten in Book Two proposes a methodological approach for reading the passage through the two frames.

When Ben Okri's youthful narrator in The Famished Road declares at the end of the novel that he desires "the liberty of limitations," (559) it is easy for the reader to give a metafictional interpretation to this statement and to use it as a lens for viewing a narrator who functions in complex and often unpredictable ways. Such an affirmation suggests that whatever the narrator's relation to a world of spirits, he has finally decided to confine himself to the real world and to use the limitations of reality as the source of a new type of freedom. This is the very basis of the writer's craft, for a writer works within the limits of artistic conventions, using and combining them to produce a potentially infinite variety of visions of the world. However, whatever the narrator's potential for becoming an African avatar of Joyce's Stephen Dedalus, a vision of Azaro as narrator that privileges his role as poet and artistic visionary would not do complete justice to the complexity of his place in Okri's novel.

The search for interpretive models capable of accounting for the nature of Okri's artistic ambitions has occupied much of the critical work devoted to his writing. Azaro has been described by José Santiago Fernández Vázquez as an African version of the type of protagonist found in the European Bildungsroman, although he exhibits some important differences in comparison with his European counterparts. Margaret Cezair-Thompson sees him as conveying postcolonial duality through his liminal state as an abiku, a child who "keeps dying and returning to the same mother, and who moves constantly between the world of spirits and the world of the living" (35). Olatubosun Ogunsanwo considers Azaro a vector of "cultural interdiscursivity" as he "bestrides the two worlds" of the novel, "the mundane world of history, stability, morality and order" and "the extraordinary world of spirits and daemons" (41; 46). For Ato Quayson, Azaro serves to draw the reader into

the communal audience requiring the same rationalizations of experience as himself. The reader is thus continually socialized into a narrative situation that combines the gnomic and proverbial affirmations of communal world-views with the growing and provisional perceptions of a limited narrative perspective. (127)

What these differing yet complementary views highlight is the necessity of observing Azaro's words and actions through several cultural and generic frames in order to grasp the complexity of his aesthetic and thematic role. All fictional texts oblige the reader to bring into play his experience of reading and an acquired cultural competence in order to make sense of the relation between the reliance on conventions and the use of innovations that gives a text its specificity. However, in the case of Okri's novel, the 
particular way in which the codes underlying the European novel and those related to an African aesthetic, be it written or oral, are brought together makes it difficult for the reader to process the relation between the realistic dimension of the narrative and what Quayson calls the "esoteric." Quayson sums up the reader's dilemma in the following way:

All the different aspects of realist narrative such as character and setting are based on the implicit belief in the knowability of the real as it unfolds its meaning in linear time. To postulate realism based on a pervasive animism is to fracture that basis of belief by suggesting that not only is the real decentered because of its permanent interplay with the esoteric, but that neither is reducible to the other. (149)

He considers that the reader must deal with "dual organizing paradigms, one of which is grounded in orality and the other in the literary" (127). The strength of Quayson's analysis of the narrative dimension of the novel comes from his familiarity with the functioning of both oral and literary conventions, allowing him to see beyond the purely thematic presence of African spirituality and to avoid the cultural pitfall of attempting to explain Okri's approach according to the codes of magical realism. A number of critics have approached the reading of The Famished Road through the frame of magical realism, a term that Okri himself rejects as inducing a purely literary reading of the novel that is not compatible with his use of what he calls an "African worldview."1 Christopher Warnes, in his discussion of Okri in relation to magical realism, is careful to point out that

[...] we need to be clear that Okri's is a faith-based, ontological magical realism, quite different from the irreverent, discourse-oriented magical realism of a writer like Salman Rushdie. (129)

If one focuses on the functioning of Azaro as narrator protagonist of the novel, it is possible to explore the expectations generated by a long tradition of fictional narrators while at the same time examining the repercussions of the use of a fictional narrator to tell a story at least partly related to a culture of orality, in which this type of narrator, who tells his own story rather than one generated by a collective consciousness, is often replaced by a narrator who speaks for the community. This approach is not intended to stand in contradiction to those cited above or to other critical methods that attempt to explain Okri's complex and surprising intertwining of diverse traditions. The purpose is rather to highlight the assumptions on which Okri's use and rethinking of the fictional narrator rely, thus making it possible to understand what form of artistic liberty Okri hopes to achieve through the limitations of two different aesthetic systems, one clearly based on literacy, the other relying on the codes of an oral culture. A close reading of Chapter Ten in Book Four, a chapter in which Azaro describes his search for his mother in the market, will make it possible to observe some of the consequences of this approach for the reading of the novel.

As Walter Ong reminds us in his discussions of the relation between orality and literacy, the conventions of novelistic representation are closely linked to the use of written as opposed to oral expression, and to the development of printing, which transformed reading into an individual practice. Ong has pointed out a number of important consequences of this process for the very type and form of literary texts, in particular

1. Expression used in an interview with Jean W. Ross, quoted in Warnes (141). 
the creation of pyramidal plots. ${ }^{2}$ Jean Derive, in his study of the relation between oral and written literature in West Africa, compares the impact of the growth of printing on the literary texts produced in Europe in the eighteenth and nineteenth centuries with the development of the novel in West Africa. Derive explains that it was precisely the temporal and spatial distance between the acts of writing and reading that led to a reinforcing of the descriptive element in literary discourse. The rise of reading as an individual act also had an effect on style, reducing the reliance on parataxis and repetition (184). In oral narrative, on the contrary, style serves not to set the fiction apart from the world it reflects, but to facilitate the creation and transmission of communal values.

In counterpoint to the spread of written and published literature, writers from areas of the world in which oral traditions are still alive have been trying to reconcile the oral tradition with the conventions of writing as a way of preserving and transmitting the specificities of an oral culture. This has produced a wide variety of attempts to create "effects of orality" in written texts. The English and French-speaking Caribbean is one of the areas where a culture of orality has produced interesting experimentations in novels by writers like Patrick Chamoiseau and Raphaël Confiant, who use creole as a vehicle for a worldview based on oral traditions. The same phenomenon can be observed in Africa. Vanessa Guignery mentions the importance for Okri of the work of Amos Tutuola, whose novel The Palm-Wine Drinkard, published in 1952, makes use of Yoruba folklore and is delivered in the voice of a narrator who makes no distinction between folktales and reality, speaking thus directly from within an African cultural frame (28).

If one observes Azaro's functioning as a narrator from within a knowledge of the ways in which an oral culture can be used in fiction, it rapidly becomes clear that Okri is not relying on the techniques that have been used by many writers to make written texts capable of reproducing the worldview on which orality relies. Derek Wright, in his discussion of orature in African literature, mentions the distinction made by Craig MacKenzie between stories that "thematize or stylize" elements of an oral culture and those in which "oral cultural forms enter performatively into the very texture of the writing, penetrating not only the subject-matter but the principles of narrative composition" (139). MacKenzie designates the former as "oral-inclusive," the latter as "oralintensive." While Quayson maintains that Okri "reproduces the oral narrator's mode of relating to the audience," there is little in the text itself to support this view. If an oral context is to be reproduced, the narrator must make explicit his relation to this context and the mode of his participation in it. Patrick Chamoiseau relies on the artifice of the "marqueur de paroles" in order to transmit the words of Solibo in Solibo magnifique. Robert Antoni, in his novel Divina Trace, also uses a homodiegetic narrator who listens to the contradictory versions of the folktales intertwined with the lives of his family. Writers like Sam Selvon and Earl Lovelace rely on the patterns of creolized English to emphasize the way in which their narrators occupy a cultural space shared with people shaped by an oral culture. Azaro, as has been pointed out by critics, speaks from no specific point in time or space, and his object cannot be said to be the transmission of an African worldview through the conventions of orality. Story-telling and myth play a vital role in the novel, but their presence is mediated by a voice which explains their presence and describes the ways in which people participate in activities related to folklore and

2. The effect of writing and printing on the form of narrative is discussed particularly in chapter 6, "Oral Memory, the Story Line and Characterization" (Ong 136-52). 
indigenous African beliefs. Azaro solicits stories from his parents, as in Chapter One of Book Two, when he begs his mother to tell him a story and she responds with the story of the man without a stomach, or when his father tells him the story of the King of the Road (298-302). He makes explicit reference to cultural practices like praying to the ancestors ("Mum was alone in the room, praying to our ancestors and to God in three different languages" 264) and to the importance of witchcraft, fetishes and masks. In terms of the African belief system, his presence is linked to the notion of the abiku, a child who comes and goes in a recurrent cycle of birth and death. At the beginning of the novel, Azaro gives the following definition of the abiku:

As we approached another incarnation we made pacts that we would return to the spirit world at the fist opportunity. [...] Those of us who made such vows were known among the Living as abiku, spirit-children. Not all people recognised us. We were the ones who kept coming and going, unwilling to come to terms with life. We had the ability to will our deaths. (4)

In defining the abiku in this way, Azaro clearly designates the frame within which he will participate in African beliefs, thereby thematizing the abik $u$ as a marker of African culture. However, although Azaro is perceived by his parents and the community in terms of his abiku identity, he creates from this identity a liminal, ambiguous space which both brings him nearer to the community and alienates him from it and which renders his narrative status problematic. Azaro's parents struggle with the anxiety linked to the belief in his abiku nature, calling on the available resources of their culture to deal with their fear:

When I recovered, however, my parents had already spent too much money on me. They were in debt. And my father, who was rather fed up with all the trouble I brought, had grown somewhat skeptical of the pronouncements and certitudes of herbalists. If you listen to everything they say, he told Mum, you will have to perform absurd sacrifices every time you step outside your door. (10)

However, Azaro for his part, will not simply hesitate between the world of spirits and the world of the living. His special gifts of perception will give him access to other ways of viewing the world, creating a profound ambiguity in his functioning as narrator. When he declares, "One world contains glimpses of others," (11) the use of the plural suggests that he will also be navigating between the world of Africa and other possible worlds, both inside and outside of Africa. This intuition is clearly borne out by the novel, which traces Azaro's life in parallel with changes taking place in Africa, suggesting the confrontation with other worlds and other worldviews. Azaro's abiku identity affects both his place in the thematic universe of the novel and his functioning as narrator, creating a bridge between the realist and animist realms of the novel but also introducing an ambiguity in the voice through which Azaro speaks.

It is from this perspective, in his speaking through the filter of his hybrid identity, that Azaro ceases to function as a purely African narrator and takes on the role and characteristics of narrators found in types of fiction that are not specific to Africa. Fernández Vázquez considers that "the protagonist's liminality emerges as a metaphorical representation of the double consciousness of the postcolonial subject" (88). He goes on to affirm that "this ambivalent status is reproduced in the style of the novel, which combines the typical details of realistic narratives with the dreamy atmosphere that characterizes the fantastic tale" (88). There is indeed a double or multiple consciousness, 
but to associate it with the postcolonial dilemma is somewhat short-sighted, for the use of Azaro's consciousness must be examined against the assumptions that underlie the use of narrators and reflectors in fiction from other times and places. Azaro brings these conventional assumptions to the reading of the novel without necessarily fulfilling the reader's expectation concerning their use. In the Bildungsroman or the Künstlerroman, it is assumed that placing the story within the words or the mind of a narrator or reflector permits the development of a counter-narrative, a discourse that allows the protagonist to develop his own particular point of view on the world in order either to adhere to the values of the society around him or to strike out on his own path. One of the most famous examples of this pattern can be found in James Joyce's A Portrait of the Artist as a Young Man. ${ }^{3}$ Unlike Stephen Dedalus, who gives the reader a view of his relation to the Catholicism and nationalism of Ireland, values to which he is finally unable to adhere, Azaro shares his perceptions but not his feelings with the reader. The reader is unable to identify a way of thinking which can be seen as the narrator's point of view and use it to understand Azaro's relation to the context in which he lives. At the beginning of the novel, he admits his own confusion as to the source and meaning of his visions and even offers the possibility that they may have been generated by his childish imagination:

I had no idea whether these images belonged to this life, or to a previous one, or to one that was yet to come, or even if they were merely the host of images that invades the minds of all children. (8)

One of the features of first-person narrators that makes them attractive to the reader is their capacity to generate poetic images and to structure them in ways that suggest alternative visions of life. The creation of a metaphorical distance between his own perceptions and the surrounding world is one of the most important strategies of a narrator/reflector; it is an important aspect of Stephen's artistic vocation, as expressed in passages like the following one:

His thinking was a dusk of doubt and selfmistrust lit up at moments by the lightnings of intuition, but lightnings of so clear a splendour that in those moments the world perished about his feet as if it had been fireconsumed: and thereafter his tongue grew heavy and he met the eyes of others with unanswering eyes for he felt that the spirit of beauty had folded him round like a mantle and that in revery at least he had been acquainted with nobility. (157)

Azaro often expresses himself through images that are as striking as those that inhabit the mind of Stephen Dedalus. If one observes Azaro's discourse, one notices that he displays not only a capacity for metaphor but a tendency to use his experience as the source of metaphors which he applies in interesting and complex ways which link him to other well-known fictional narrators. At the beginning of the rainy season, in Chapter Five of Book Four, Azaro compares the onset of the storm with a photograph: "The world was still, as if it had momentarily become a picture, as if God were The Great Photographer" (328). Given his close relationship with the photographer, who plays an important role in the novel, this remark reveals Azaro's understanding of the way in which photography modifies the perception and representation of reality. In the context of a chapter that begins with the sentence, "I remember the day distinctly when,

3. The famous final passage of this novel, in which Stephen Dedalus evokes his desire to "forge in the smithy of my soul the uncreated conscience of my race," figures as epigraph to Okri's novel The Landscapes Within. 
on my way back from school, great crashing noises exploded over the forest," (328) it also shows that he is able to understand the importance of specific moments, and to contrast them with the mythical and cyclical visions of time that characterize African mythology. Later in the same chapter he sees the action of the rain as transforming the road into "what it used to be, a stream of primeval mud, a river," and he speaks of "wading in the origins of the road" (330). In the same chapter he will also evoke the cyclical nature of the seasons and its relation to a collective consciousness ("During the harmattan we always forget the rainy season" 329). At the end of the chapter, the description of the way in which the flooded road swallows the white engineer creates a powerful image of the futility of progress in the face of the forces of nature. While all of these perceptions of time can be perceived in his description of the onset of the storm, the chapter does not contribute to the defining of a point of view which would either make of Azaro a defender of his community and its African culture or serve as the metaphorical and poetic basis of a more personal perception of the world. The two strands remain firmly entwined. No "mantle" of beauty is folded around him as is the case for Stephen Dedalus. Furthermore, the following chapter, in which Azaro finds himself in Madame Koto's room, confronts Azaro, and the reader, with a complex set of images strongly marked by the esoteric. The reader is hard put to establish a narrative or aesthetic bridge with the preceding chapter.

As a narrator and protagonist, Azaro is clearly not following a set path toward personal fulfillment or the development of a coherent and personal view of the world. Nor is he storing experience in his memory to be used to construct his own aesthetic vision of the world, in the guise of Proust's Marcel or Joyce's Stephen. Yet he borrows characteristics of the narrative voices found in classical fiction while eschewing the adoption of a voice that could be considered the vehicle of an oral culture. Although he seems to possess a vocabulary and experience which blur the distinction between the voice of the child and that of the adult, there are moments when he rigorously refuses to see beyond the visual range of the child, as in the chapter in which he evokes the party at Madame Koto's bar (Book Four, Chapter Two). This is clearly a story of sexual awakening, but Azaro does not place it in that perspective, once again evoking a change in the world: "Then one afternoon time moved and something happened in the world" (312). It is the other characters involved who will put names on what is occurring ("Watch your women-o! There's a small boy here who wants to fuck!” [313]; “"This is a party,' she said” [317]; “"It's landed on the gramophone!' someone cried” [318]). Most importantly, Azaro in leaving the bar simply remarks that "The women stayed behind" (318). Another person in the next chapter will ask whether "Madame Koto now has prostitutes in her bar" (322). These are classic strategies for exploiting the limited point of view of the narrator as child, withholding the adult perspective and carefully placing it in the words of other characters. But once again this narrative strategy is confined to specific moments that stand in striking contrast to others.

It is clear that Azaro as narrator cannot be understood within the frame of any single narrative genre, be it realist, picaresque, postmodern, postcolonial or magical realist. Nor can he be seen as consistently conveying a worldview based on an African cosmology and expressed through an aesthetics of orality. Yet all of these paradigms must be mobilized in the reading of the novel. An examination of a passage involving several of these frames can demonstrate the reading strategies necessary for evaluating 
their respective roles. In Chapter Ten of Book Two, Azaro finds himself in the market and sets off in search of his mother. The passage involves both a description of the market and a quest for a lost parent, a theme that relies both on the motif of the abiku and the preoccupation of many folk and fairy tales with separation from a parent. The descriptive aspect can be seen as a reflection of Azaro's realist function, as the eye-witness to a specific reality, represented here by the African market. Description is an important element of realist fiction, in which the mastery of a world through perception, its reduction to the visible and intelligible, plays a significant role. In his study of description, Philippe Hamon explains that in realist fiction, description serves "to neutralize falsehood, to create a truth effect" (51 my translation). He points out that it implies a certain competence on the part of the narrator, a taxonomic knowledge of the world, and that it creates a potential tension between the descriptive (paradigmatic) and narrative (syntagmatic) dimensions of a text. One of Azaro's primary functions in Okri's novel is to describe the world, or rather worlds, he inhabits. He often does this in considerable detail, his roving eye exploring the multiple dimensions of a complex reality. His description of the market relies on two important functions of the market in an African context as a reflection of the natural "fecundity" of the natural context and of the struggle to transform this fecundity into the means of commercial survival. He evokes "the smells and aromas of the marketplace, the rotting vegetables, the fresh fruits, the raw meat, roasted meat, stinking fish, the feathers of wild birds and stuffed parrots, the wafting odours of roasted corn and fresh-dyed cloth" (190). But he also mentions that "there was much bickering in the air and rent-collectors hassled the women and cart-pullers shouted for people to get out of their way" (190). If this description fulfills the "horizontal" function which Hamon sees in the way description treats the referent as "a surface, a space, rationalized and rationalizable," (60-1) it also fulfills the "vertical" function of seeking a meaning behind deceptive appearances (62). The violence and confusion of the market are mirrored metaphorically in Azaro's vision of "basins where great crabs and giant lobsters were entangled in their mass of claws, in buckets where hammer-headed fishes and eels whipped their tails against the aluminum" (190-1). Yet this description will not suffice to provide Azaro with the clue to the link between the chaotic market and his mother's attempts to survive in the face of people who attempt to prevent her from keeping her stall in the market. In order to perceive what is happening to his mother, Azaro will have to yield his powers of sight and description to another vision of the market, in which the real and spiritual worlds come together. He sees a herbalist whose stall "was the quietest place in the market. He sat alone on a bench. He called no one to buy his wares and no one came" (191). Azaro accepts food and water offered by the herbalist and falls into a trance in which his own mind and body become the meeting point between the real world and the realm of the spirits. Passages of this type are difficult to interpret because they are not anchored strictly speaking in the consciousness of the narrator. However, in the passage that follows Azaro's exploration of the market, the notion of voice can be seen as a bridge linking his search for his mother to the revelation at the end of the chapter of what has happened to her and why she disappeared. Beyond the fact that seeing and hearing (along with smelling) dominate the sensory world of Okri's novel, sound and voices are important components of the oral world of ritual and folklore that underlie the spiritual dimension of Okri's novel. The polyphony that characterizes The Famished Road does 
not so much confront differing social dialects as mix codified uses of verbal interchange with ordinary dialogue. There are numerous examples of dialogues between Azaro and real people or spirits in which the use of questions, riddles and verbal exchange are clearly reflections of the role played by such uses of language in folklore. In one of his encounters with the spirits, Azaro sees a giant turtle who asks him a series of questions:

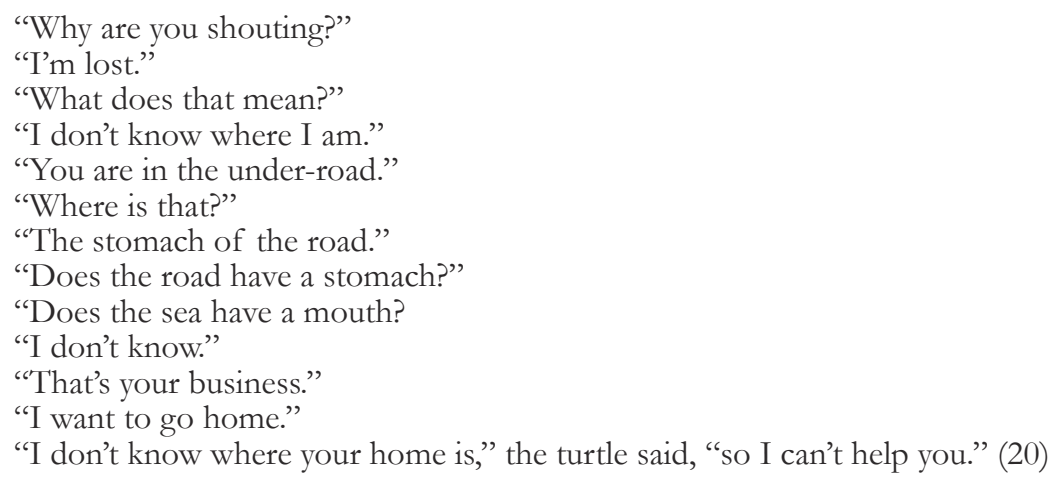

That the ability to enter into this type of dialogue and follow lines of reasoning that are more verbal and intuitive than realistic can be seen in Azaro's answer to Madame Koto, when she tells Azaro:

"If you misbehave the same thing will happen to you."

"What?"

"The forest will swallow you."

"Then I will become a tree."

"Then they will cut you down because of a road."

"Then I will turn into the road." (255)

In the passage involving Azaro's search for his mother, the transition from the visual experience of the market to the esoteric world represented by the herbalist is signaled by the sounds that Azaro hears inside the herbalist's tent: "The noise kept changing into the spectral sound that only spirits can make" (192). The herbalist questions Azaro in a way that resembles the passages cited above. The herbalist attempts to elicit responses that go beyond the surface of Azaro's search for his mother, interrogating its deeper meanings:

He looked at me again, as if I were some sort of sign.

"Are you clever at school?"

"I'm looking for my mother."

"Does your mother teach you things?"

"Yes."

"Like what?"

"How to fly to the moon on the back of a cricket." (193)

After Azaro drinks the water offered by the herbalist and falls into a trance, he hears voices from the spirit world talking about him and his mother. The voices offer clues to the relation between Azaro's search for his mother and the larger social issues evoked in the novel:

\footnotetext{
"Strange things are happening to us."

"To our children."

"They say he is looking for the spirit of Independence."
} 
"They say he is looking for himself."

"For his own spirit."

"Which he lost when the white man came."

"They say he is looking for his mother." (196)

The conversation carried on by the voices, by adopting the preoccupations of Azaro and mixing them with interrogations about the fate of the nation, effectively links the narrative logic of Azaro's search for his mother with elements of the larger context of which Azaro can have no personal understanding, and to which he could not logically give verbal expression. The cryptic conversation taking place among the spirits, compared by Azaro to "a numinous ritual," (196) links this moment to the type of questioning and dialogue found in other passages of the novel. ${ }^{4}$ The passage creates an interface between the realistic dimension of Azaro's functioning as a narrator and the multiple aspects of the spiritual world that belong to a collective consciousness and an oral tradition rather than to the individualistic perspective associated with the narrator of realist fiction. Rather than describing his experience, Azaro draws the reader into the experience of listening to the voices of the spirits. In this type of passage, Quayson's argument that Okri socializes the reader into a world governed by the logic of orality does indeed find a demonstration. Azaro's consciousness becomes the receptacle for voices that belong to the world of spirits rather than to individual awareness. The passage clearly expresses the idea that a full understanding of the world requires a willingness to listen to the voices generated by one's own culture. Furthermore, it solicits from the reader a capacity to hear echoes from other passages, revolving around the use of motifs like the moon and the story of the cricket, rather than on a linear reading based on a logic expressing itself solely through the voice of a narrator constructing his own view of the world. ${ }^{5}$

While Ben Okri himself said that he was expressing himself "from the inside of the African worldview," (Interview with Jean W. Ross, qtd. in Warnes 337-8) the use that he makes of this worldview in aesthetic terms is more oblique and allusive than what is often found in fiction from Africa or the Caribbean. The blending of elements from African culture with techniques borrowed from European fiction is so seamless that it is often difficult to clearly identify the moments of transition between the real and the spiritual domains. And while the overall impression of the novel is episodic, a close examination reveals ways in which Azaro matures and integrates an understanding of the larger world into his own perspective. Reading Azaro's statement about the "liberty of limitations" in a metafictional perspective involves accepting the essentially paradoxical relation between the constraints of fiction and the unlimited nature of reality, a reality to which Okri hopes to give the reader a glimpse. But it also implies a capacity on the part of the reader to bring into play his own cultural background as a model for reading

4. The reference to ritual can be related to what Mark Mathuray considers an important dimension of African spirituality. Mathuray sees Azaro's "fluid to-ing and fro-ing" as "culturally incongruous" in a society in which "crossing over into the sphere of the spirits requires ritual and ontological transformations" (123). In this passage the ritual transition is specifically marked.

5. Quayson points out the importance of this type of narrative organization, which is based on association rather than on linear logic, and which he sees as a mark of orality: "The paratactic quality of oral narratives seems to derive directly from the fact that they are constructed as a collection of items that have been secreted in collective memory as expressive of significant cultural or social insights. These become nodal points for the organization of discourse in oral contexts and need not be tied to temporal criteria" (130). 
the novel, while at the same time accepting the idea that certain aspects of the novel require a receptivity to other models, generated within other cultures.

Kathie BIRAT

Université de Lorraine

\section{Works Cited}

Antoni, Robert. Divina Trace. Woodstock, NY: Overlook Press, 1991.

Cezair-Thompson, Margaret. "Beyond the Postcolonial Novel: Ben Okri's The Famished Road and its 'Abiku' Traveller." The Journal of Commonwealth Literature 31.2 (1996): 33-45.

Chamoiseau, Patrick. Solibo magnifique. Paris : Gallimard, 1988.

Derive, Jean. "Imitation et trangression: de quelques relations entre littérature orale et littérature écrite en Occident et en Afrique." Oralité et literature: Echos, écarts, resurgences. Nicole BeLmONT et JeanMarie Privat, eds. Cabiers de littérature orale, no. 56, 2004: 175-200.

Fernández VÁzquez, José Santiago. "Recharting the Geography of Genre: Ben Okri's The Famished Road as a Postcolonial Bildungsroman." The Journal of Commonwealth Literature 37.2 (2002): 85-106.

Guignery, Vanessa. Seeing and Being: Ben Okri's The Famished Road. Paris: PU de France, 2012.

Hamon, Philippe. Du descriptif. 1981. Paris: Hachette, 1993.

Joyce, James. A Portrait of the Artist as a Young Man. 1916. London: Guild Publishing, 1978.

Ogunsanwo, Olatubosun. "Intertextuality and Post-Colonial Literature in Ben Okri's The Famished Road." Research in African Literatures 26.1 (Spring 1995): 40-52.

Okri, Ben. The Famished Road. 1991. London: Vintage, 2003.

ONG, Walter. Orality and Literacy: The Technologizing of the Word. 1982. London: Routledge, 2002.

Mathuray, Mark. On the Sacred in African Literature: Old Gods and New Worlds. London: Palgrave, Macmillan, 2009.

Quayson, Ato. Strategic Transformations in Nigerian Writing. Orality and Hsitory in the Work of Rev. Samuel Johnson, Amos Tutuola, Wole Soyinka and Ben Okri. Oxford: James Currey, 1997.

Warnes, Christopher. Magic Realism and the Postcolonial Novel: Between Faith and Irreverence. Basingstoke: Palgrave Macmillan, 2009.

Wright, Derek. Contemporary African Fiction. Bayreuth African Studies 42. Bayreuth: Bayreuth U, 1996. 